\title{
HIV Prevention and Rehabilitation Models for Women Who Inject Drugs in Russia and Ukraine
}

\author{
Roman Yorick,, ${ }^{1,2}$ Halyna Skipalska, ${ }^{3,4}$ Svetlana Suvorova, ${ }^{2}$ Olga Sukovatova, ${ }^{1,2}$ \\ Konstantin Zakharov, ${ }^{1,2}$ and Sara Hodgdon 5 \\ ${ }^{1}$ HealthRight International, Representative Office in the Russian Federation, 7 Lev Tolstoy Street, Office 701, \\ St. Petersburg 197376, Russia \\ ${ }^{2}$ Doctors to Children, 7 Lev Tolstoy Street, Office 707, St. Petersburg 197376, Russia \\ ${ }^{3}$ HealthRight International, Representative Office in Ukraine, 3-7 Stanislavsky Street, Kyiv 01001, Ukraine \\ ${ }^{4}$ Ukrainian Foundation for Public Health, 3-7 Stanislavsky Street, Kyiv 01001, Ukraine \\ ${ }^{5}$ HealthRight International, 65 Broadway, 19th Floor, New York, NY 10006, USA
}

Correspondence should be addressed to Roman Yorick, info@healthright.org

Received 4 September 2012; Revised 22 October 2012; Accepted 24 October 2012

Academic Editor: Thomas F. Kresina

Copyright () 2012 Roman Yorick et al. This is an open access article distributed under the Creative Commons Attribution License, which permits unrestricted use, distribution, and reproduction in any medium, provided the original work is properly cited.

\begin{abstract}
Women who inject drugs require gender-specific approaches to drug rehabilitation, modification of risk behaviors, and psychosocial adaptation. Improved outcomes have been demonstrated when the specific needs of women's subpopulations have been addressed. Special services for women include prenatal care, child care, women-only programs, supplemental workshops on women-focused topics, mental health services, and comprehensive programs that include several of the above components. To address the special needs of women injecting drug user (IDU) subpopulations, such as HIV-positive pregnant women and women with young children, recently released female prisoners, and street-involved girls and young women, HealthRight International and its local partners in Russia and Ukraine have developed innovative service models. This paper presents each of these models and discusses their effectiveness and implementation challenges specific to local contexts in Russia and Ukraine.
\end{abstract}

\section{Introduction}

The prevalence of injecting use of opioid substances among people 15-64 years of age is estimated at $0.9 \%$ in Ukraine and $2.29 \%$ in Russia [1]. There is no reliable data on gender distribution of IDUs in the region. Global trends suggest that drug use in general is more prevalent among boys and men than among girls and women [2]. Some data from the region demonstrate that women constitute between 20 and $30 \%$ of IDUs [3,4]. The HIV epidemic in Russia has been closely linked with IDU: $56.2-61.3 \%$ of newly reported HIV infections in 2008-2011 were attributed to IDUs [5]. In Ukraine, heterosexual sex has been the predominant route of HIV transmission since 2008, but drug use is still a key force in the epidemic, with $38.4 \%$ of new infections occurring in IDUs in 2011 [6]. The midestimates of HIV prevalence in IDUs in the region are close to $40 \%$ [7].
Female sub-populations with the highest prevalence of injecting drug use and HIV in the region include commercial sex workers (CSWs) and those who engage in transactional sex, street-involved girls and young women, and prisoners. These groups are highly intertwined. Among CSWs, 18$70 \%$ inject drugs [8-10]; among IDUs, some $40 \%$ report transactional sex [11]. Among street children and youth, approximately one-third are female; $20-50 \%$ have experience of injecting drug use, and 5-10\% report transactional sex [12-14]. Women constitute $5.3 \%$ and $8.2 \%$ of the prison populations in Russia and Ukraine, or 60 and 8 thousand women prisoners, respectively [15]. There are no reliable national data on the proportion of IDUs among prisoners in the region. In some regions of Russia and Ukraine, the proportion of IDUs among inmates is greater than $10 \%$, HIV prevalence in prisons is greater than $10 \%$, and HIV prevalence among inmates who have used injecting drugs is close to $50 \%$ [16]. Evidence from other parts of the world 
suggests that, compared to men, a larger proportion of women in prisons is convicted for drug-related crimes, and between 20 and 70 percent of women in prisons are drugdependent [17-20].

A number of studies conducted within the last 20 years have addressed gender differences in the needs, experiences and rehabilitation approaches for drug users [21-23]. In particular, women start using drugs later than men, and their addiction progresses much faster. Women's substance abuse practices are formed by their male partners. Women demonstrate a much higher prevalence of psychiatric conditions, such as depression, that coexist with and predate substance abuse [24]. Women are less likely than men to access drug rehabilitation treatment, and for this treatment to be effective it has to address the needs of specific subgroups of women. Special services for women include prenatal care, child care, women-only programs, supplemental workshops on women-focused topics, mental health services, and comprehensive programs that include several of the above components [25].

To address the needs of drug-using women in Russia and Ukraine, the global health and human rights organization HealthRight International and its local implementing partners developed a model to assist HIV-positive pregnant women and women with young children (MAMA+), a model for psychosocial adaptation of recently released female prisoners, and comprehensive services to assist street-involved girls and young women.

Medication-assisted treatment for women IDUs is an important asset to psychosocial rehabilitation services. As most IDUs in Russia and Ukraine are opioid-dependent, they can benefit from opioid substitution therapy (OST). In Russia, however, OST is not permitted, with methadone being on the list of illegal substances and buprenorphine not approved for OST [26]. The only other medication option for opioid-dependent IDUs is the opioid antagonist naltrexone. Despite a number of studies in Russia demonstrating its effectiveness in preventing relapse in heroin users [27-31], naltrexone remains largely unavailable due to its prohibitive cost: a recommended nine-month treatment course costs over $\$ 6,000$ [32]. In September 2012, naltrexone became available in St. Petersburg through a government-funded program to just $40 \mathrm{HIV}$-positive IDUs a year citywide to prevent the spread of HIV [33].

In Ukraine, OST with buprenorphine has been available since 2004, with methadone added in 2008 [30]. Early OST rollout data showed that women, particularly pregnant women and women with young children, were not accessing OST in proportion to their presence in the IDU population $[4,34]$. A number of restrictions apply to OST access in Ukraine raising the entry threshold for potential participants. Among others, these limitations include the requirement to produce an identification document, which many IDUs do not have, or present a certificate of two unsuccessful attempts of nonmedicated rehabilitation within the last year [35]. The MAMA+ for IDUs model in Kyiv worked to overcome these shortfalls by incorporating OST as an important component of psychosocial rehabilitation of women IDUs [33, 35].

\section{MAMA+: Comprehensive Assistance to HIV-Positive Pregnant Women and Women with Young Children}

The MAMA+ model was initially developed in 2004 in St. Petersburg, Russia, to prevent child abandonment by HIV-positive mothers. That year, the rate of child abandonment by HIV-positive women in St. Petersburg was $11.7 \%$, ranging from $5.5 \%$ in noninjectors to $15.6 \%$ in IDUs [36]. HealthRight, the St. Petersburg-based NGO Doctors to Children (DTC), and government Centers of Social Services for Families and Children in three districts of the city implemented the MAMA+ model to deliver psychosocial services for HIV-positive women at high risk of child abandonment. Other partners include the city infectious disease hospital where women with known HIVpositive status deliver and the only two maternity hospitals in the city that admit women for delivery who have not previously accessed prenatal care. These two high-risk maternity hospitals provide women in labor with counseling and rapid testing for HIV. This allows for catchment of all HIV-positive pregnant women perinatally. Prenatal clinics or women's consultancies and NGOs serving IDUs and people living with HIV were later added to the referral network to allow for earlier identification of HIV-positive pregnant women. Risk factors for abandonment include expressed intention to abandon, injecting drug use, depression, no stable housing, family violence, and lack of support from family members. Initial screening is conducted by healthcare staff who refer at-risk women to professional counselors. After additional screening, motivational interviewing, and crisis psychological counseling, the counselor asks the woman to sign an informed consent for services.

The model is comprised of the following components (Figure 1): (1) home-visiting services; (2) child daycare at the MAMA+ center; (3) halfway house residential support for pregnant women and women with young children; (4) counseling and referral to government and communitybased drug treatment programs; (5) social counseling, referral and escort to government institutions to process paperwork, apply for housing, receive government child allowance, and so forth; (6) school for young mothers on child care, parenting, and HIV-related issues in children; (7) workshops on women's issues, such as improving selfimage and self-esteem, coping with family violence, and building independence; (8) workshops for family members on HIV, care and support for women and children affected by HIV, and substance codependence; (9) vocational counseling and job placement for women and family members; (10) peer support groups for women, their partners, and other family members; (11) peer counseling by former MAMA+ clients. This model is implemented by a multidisciplinary case management team comprised of at least one of each of the following professionals and supplemented by peer volunteers: social workers, psychologists, child development specialists, medical providers (nurse or nurse practitioner), and lawyers. All services are provided according to a multidisciplinary case management protocol (Figure 2), which has 


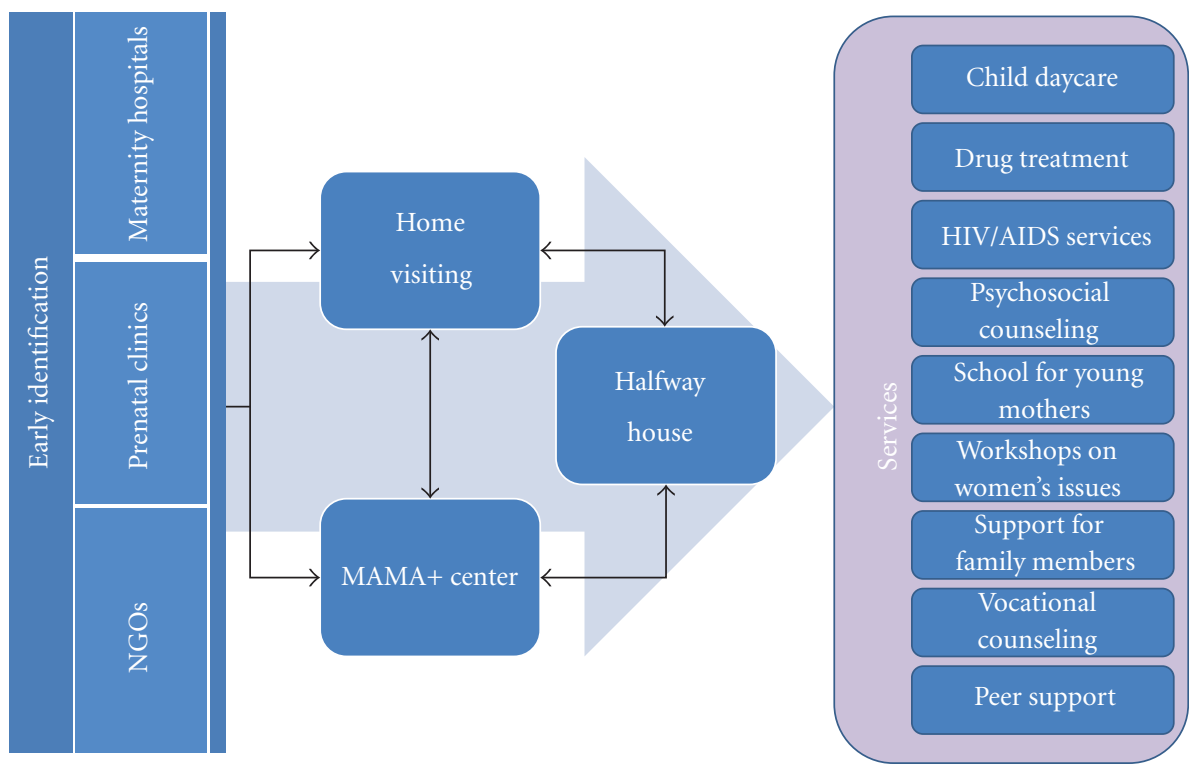

Figure 1: MAMA+ model.

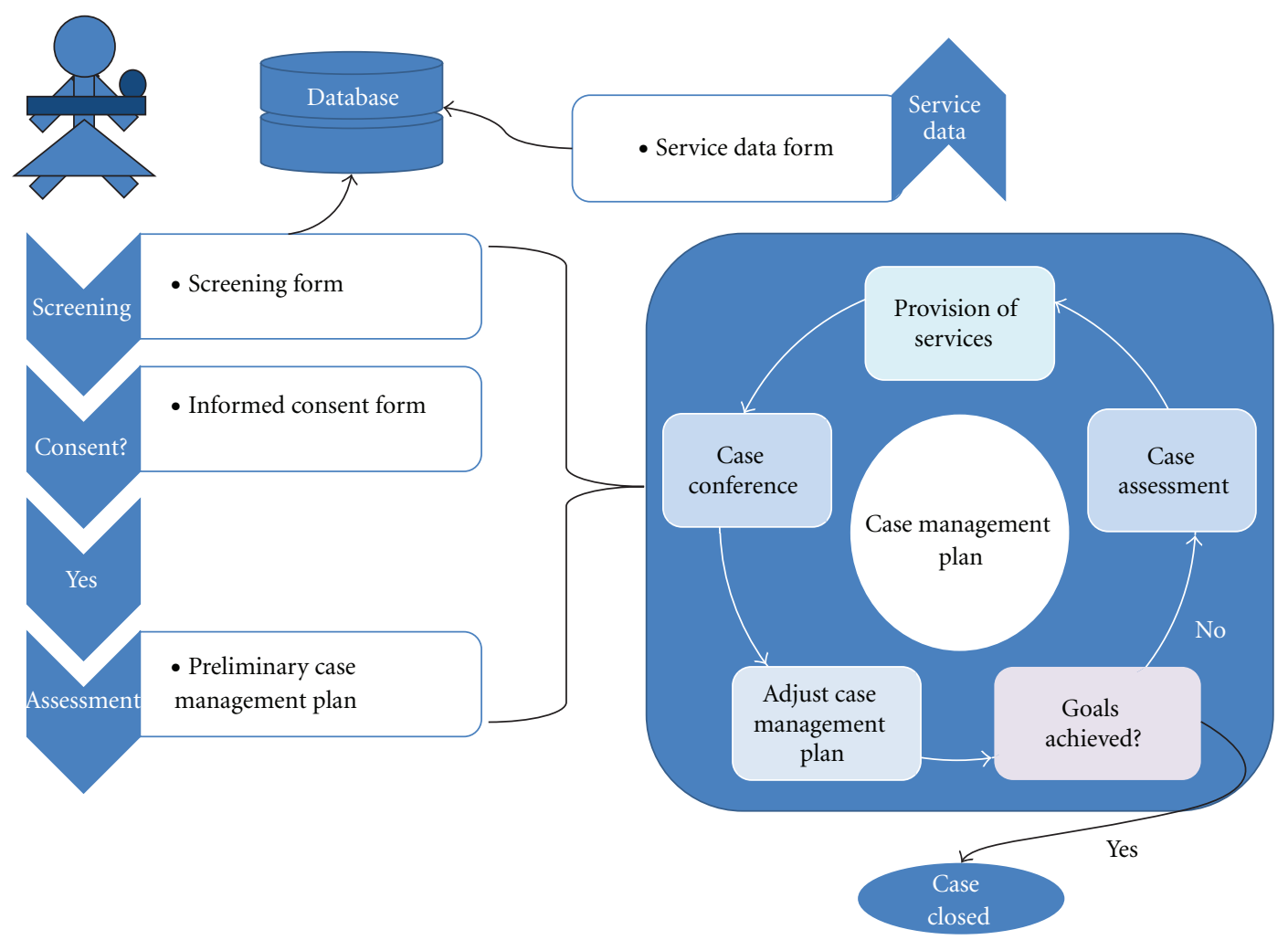

FIgure 2: Case management protocol.

been documented and published in Russian and Ukrainian [37, 38].

In Russia, the MAMA+ model has been implemented in the cities of St. Petersburg and Yekaterinburg in partnership with NGOs and government Centers of Social Services for
Families and Children. The network of government social service facilities has been the single most important factor contributing to the model's sustainability in Russia. Most components of the MAMA+ model have been institutionalized as part of government Centers of Social Services, with 
437 government providers receiving training and supervision from HealthRight and DTC in 2007-2012. In 2005-2011, 808 HIV-positive women and their children and other family members received MAMA + services in St. Petersburg, with a specific emphasis on drug-using women as most atrisk of child abandonment. The proportion of IDUs among HIV-positive pregnant women in St. Petersburg decreased from $62.3 \%$ in 2004 to $40.9 \%$ in 2008 [36]. At the same time, IDUs constituted approximately $80 \%$ of MAMA+ clients in St. Petersburg [37]. As a result, child abandonment by HIVpositive women decreased from $11.7 \%$ in 2004 to $6.0 \%$ in 2008 , with the most significant decrease of the abandonment rate among injecting drug users, from $15.6 \%$ to $9.9 \%(P=$ 0.009) [36]. In 2010-2012, as a result of MAMA+ replication in the city of Yekaterinburg, child abandonment rates among HIV-positive women dropped from $6.3 \%$ in 2009 to $1.9 \%$ in $2011(P=0.0037)$ [39]. Most HIV-positive women who abandon their children, even with available MAMA+ services, are active IDUs who do not access prenatal care. They learn about their HIV status in the maternity hospital and leave the hospital within hours after delivery seeking their next dose of illicit drugs, as opioid substitution therapy (OST) is not available in Russia [40, 41].

In Ukraine, where MAMA + was replicated in 2005 in the cities of Kyiv, Donetsk, and Simferopol, OST with buprenorphine has been available since 2004, with methadone added in 2008 [40]. Originally, only 25\% of MAMA+ clients in Ukraine were IDUs, reflecting the national trends of the HIV epidemic $[6,42]$. Injecting drug use, however, has been identified as the single most important risk factor for child abandonment by HIV-positive women in Ukraine [43]. Thus the MAMA+ model, which was implemented in partnership with the All-Ukrainian Network of People Living with HIV (AUN) and the Ukrainian Foundation for Public Health, was adapted for IDUs in Kyiv city. Services added to better meet the needs of IDUs included counseling by a drugabuse physician (narcologist), referral to OST programs, and a peer support group for IDU pregnant women and women with young children [44, 45]. In 2008-2010, 100 female IDUs who were pregnant or had young children, as well as 139 of their family members received MAMA+ for IDUs services, and 14 women were linked with OST programs in Kyiv [46]. Unlike in Russia, where the model benefitted from government investment in a social service system, the main factor of model sustainability in Ukraine has been local NGOs and international donors. The AUN has disseminated the MAMA+ model across Ukraine beyond the original three cities and has continued to support MAMA+ for IDUs in Kyiv.

\section{Psychosocial Adaptation of Recently Released Female Prisoners}

To respond to the specific needs of female prisoners, such as HIV/AIDS, sexual and reproductive health concerns, drug use, child custody, family support, and other issues [17, 47], HealthRight, in partnership with DTC and regional social protection and penitentiary authorities, developed a model on psychosocial adaptation of recently released female prisoners. The model was implemented in 20102012 in a medium-security female penitentiary facility in the Leningrad region near St. Petersburg. Among 800-1,200 inmates, $67 \%$ are under the age of $35 ; 51 \%$ have children under 18 ; over $60 \%$ were sentenced for drug-related crimes, many of whom have experience of injecting drug use; $37 \%$ are HIV-positive; $45 \%$ of those who are positive require ARV treatment.

The model components include the following (Figure 3): (1) a specialized Department for Social Adaptation (DSA) of recently released female prisoners at the government Crisis Center for Women in St. Petersburg; (2) prerelease school at the penitentiary facility conducted by DSA staff; (3) individual psychosocial counseling at the penitentiary and after release; (4) group training activities on HIV prevention, drug abuse, sexual risks, and other risky behaviors before and after release; (5) laboratory monitoring of immune status, consultations by an infectious disease specialist, and access to ARV treatment for HIV-positive women in prison; (5) peer support groups for IDUs and HIV-positive women at the penitentiary and at the DSA upon release; (6) psychosocial support upon release to secure necessary documents, housing, employment, child custody, and so forth; (7) referral and support in accessing government and NGOrun drug rehabilitation programs and community-based twelve-step programs; (8) referral for AIDS Center services, ARV treatment, and support in treatment adherence; (9) psychosocial counseling and peer support groups for family members of prisoners.

The team of providers is comprised of the team leader (head of the DSA), DSA social workers and psychologists, penitentiary counselors, and a DSA lawyer. All services are provided according to the case management and crossreferral protocol, which was approved by the regional social protection and penitentiary authorities and published in the form of methodological recommendations for social service providers and penitentiary staff [48].

Over two years, over 1,200 women received services in the penitentiary facility regardless of their HIV or IDU status, and 287 (or 24\%) accessed services in St. Petersburg upon release. This access rate is comparable to the $30 \%$ rate of access to HIV services reported in the United States for HIV-positive recently released inmates $[49,50]$. A key factor of success in linking former female prisoners to services is utilization of the same staff who established a rapport with inmates before release to provide services after release. Access to postrelease services is impeded by the fact that over $30 \%$ of the inmates at the facility in the Leningrad region are not from St. Petersburg and so do not seek services in the city upon release. Linking IDUs to residential drug treatment programs immediately upon release has been crucial in preventing relapse. Access to HIV treatment and care for female prisoners in Russia has been significantly impaired in 2011-2012 by the reform that transferred penitentiary healthcare to the responsibility of the civilian healthcare system, but failed to effectively link civilian providers with prison populations. 


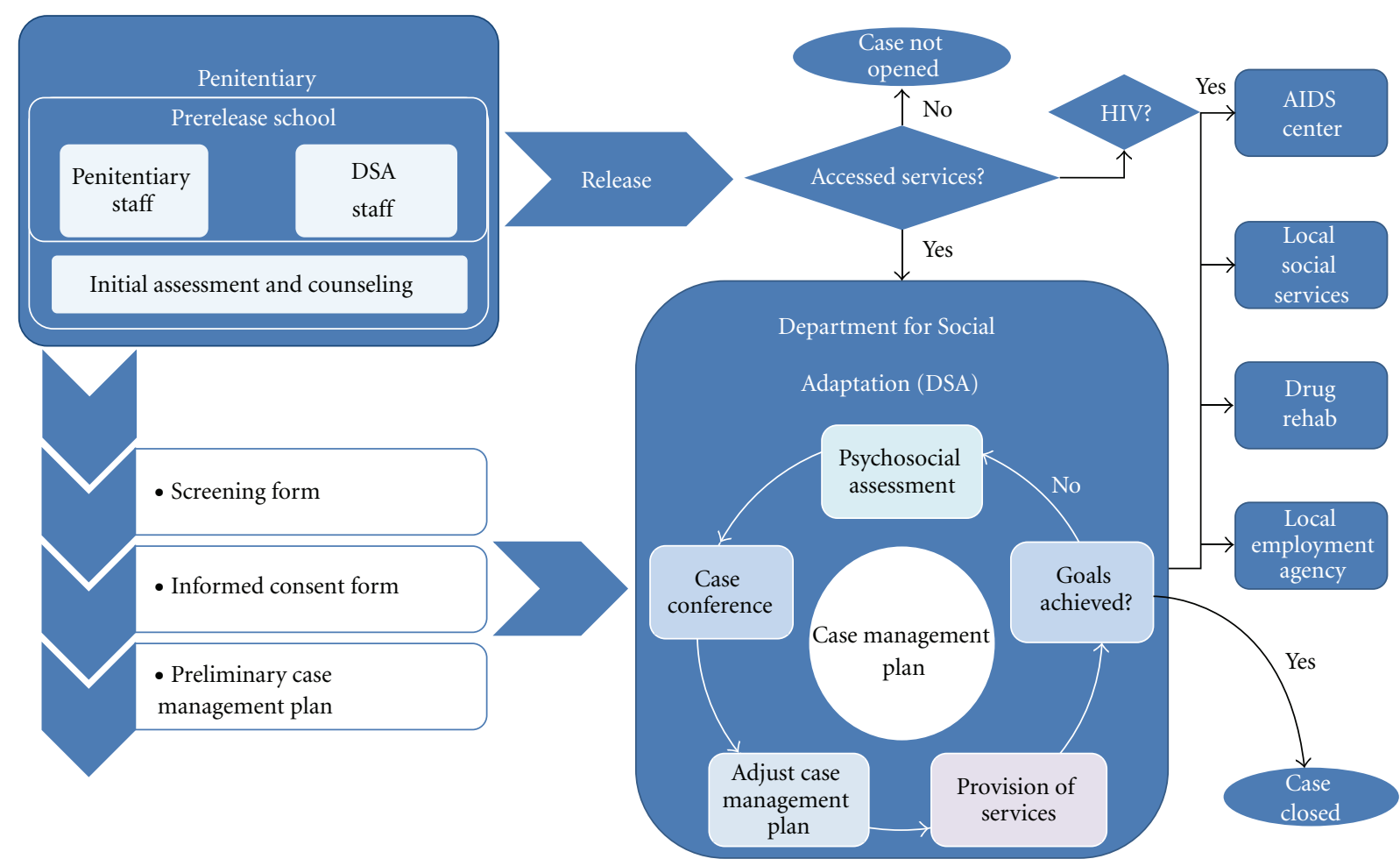

Figure 3: Psychosocial adaptation of recent female prisoners.

\section{Comprehensive Services for Street-Involved Girls and Young Women}

HealthRight and the US Centers for Disease Control and Prevention conducted an HIV seroprevalence study among street youth in Ukraine in 2008, which demonstrated that girls are at a significantly higher risk of HIV, suggesting the need to implement services specifically targeting streetinvolved girls and young women [13]. In response, in 2010-2011 HealthRight in partnership with the Ukrainian Foundation for Public Health and the government Kyiv City Center of Social Services for Families, Children and Youth developed a model serving street-involved girls and young women. The model includes the following components (Figure 4): (1) street outreach by partner organizations providing psychosocial counseling to all street youth and referral for street-involved girls and young women to the project drop-in center (DIC); (2) low-threshold DIC where clients receive access to a safe space, shower, clean clothes, snacks, and case management services; (3) halfway house residential support for street-involved girls and young women (this component is currently in development); (4) psychosocial counseling for girls and young women on government paperwork, housing, education, employment, and other issues; (5) voluntary counseling and rapid testing for HIV, STIs and pregnancy at the DIC, and referral to specialized clinics; (6) behavior change communication intervention entitled STEPS to reduce HIV and other risks, which was developed specifically for street youth [51-54]; (7) training activities and workshops on women-related topics, such as

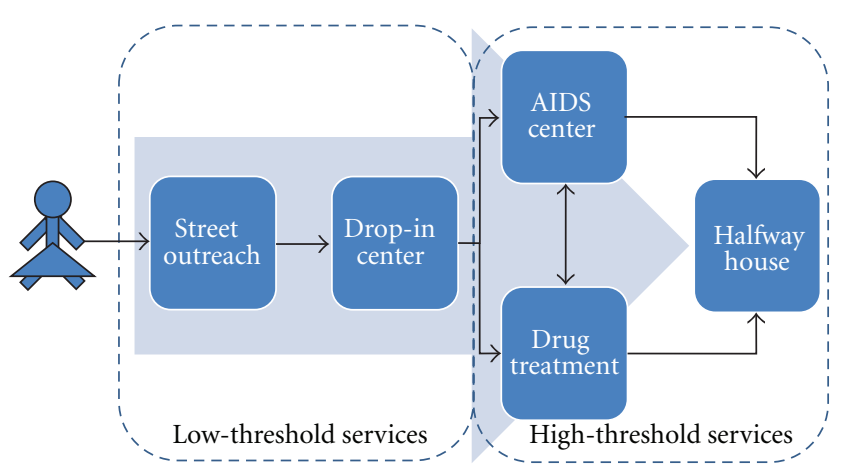

FIGURE 4: Comprehensive services for street-involved girls and young women.

gender-based violence, sexual and reproductive health, selfimage and self-assurance; (8) peer support groups for girls and young women; (9) referral to drug abuse rehabilitation and OST, where appropriate; (10) services for male partners of DIC clients, including counseling, education, and group activities.

Services are provided according to a case management protocol to assist street youth, which was documented and published in Russian and Ukrainian [55-58]. The case management team includes the team leader, a medical provider (nurse), social workers, psychologists, and a lawyer. Since 2012, the DIC and its entire staff have been integrated into the government Kyiv City Center of Social Services. In 2010-2011, 759 girls and young women received services. 
Of them, $42 \%$ sleep on the streets, in basements, attics, or abandoned buildings; $13 \%$ are substance users; 39\% have children of their own; $26 \%$ are HIV-positive [59].

This gender-sensitive model of services for streetinvolved girls and young women was developed from a coeducational model implemented earlier in Russia and Ukraine [54-57]. The gender-specific approach has proven successful in making services more attractive and accessible for female clients, providing counseling and group activities on woman-related topics, and addressing some specific needs of women, such as pregnancy and sexual health in a woman-friendly atmosphere. At the same time, it has proven unproductive to exclude male partners of DIC clients from counseling services and group activities, as streetinvolved girls and women are often dependent on men in their sexual, drug using, and other behaviors, as well as for protection and financial support. Coeducational service facilities are required to provide psychosocial rehabilitation and support to street youth, with special attention to gender-sensitive topics addressed in separate and mixed-sex groups.

\section{Acknowledgments}

The authors would like to acknowledge Johnson and Johnson, M-A.C AIDS Fund, USAID, and the World Childhood Foundation for their support of the MAMA+ development, dissemination, and replication in Russia and Ukraine; the Open Society Foundations for their support of the MAMA+ for IDUs in Kyiv, Ukraine; the Elton John AIDS Foundation (EJAF) and UNODC for their support of the model for social adaptation of recent female prisoners in St. Petersburg, Russia; EJAF for its support of the Service Center for Girls and Young Women in Kyiv, Ukraine.

\section{References}

[1] UNODC, World Drug Report 2012, United Nations Publication, Sales No. E.12.XI.1, http://www.unodc.org/unodc/ secured/wdr/Prev_All_2012.pdf.

[2] L. Degenhardt and W. Hall, "Extent of illicit drug use and dependence, and their contribution to the global burden of disease," The Lancet, vol. 379, pp. 55-70, 2012.

[3] C. Aceijas, S. R. Friedman, H. L. F. Cooper, L. Wiessing, G. V. Stimson, and M. Hickman, "Estimates of injecting drug users at the national and local level in developing and transitional countries, and gender and age distribution," Sexually Transmitted Infections, vol. 82, supplement 3, pp. iii10-iii17, 2006.

[4] Analytical Report, Monitoring of Behavior of Injecting Drug Users as a Component of the Second Generation Epidemiological Surveillance, International HIV/AIDS Alliance in Ukraine, Kyiv, Ukraine, 2005, http://www.aidsalliance.org.ua/ ru/library/our/monitoring_reports/pdf/idu.pdf.

[5] Russian Federal AIDS Center, HIV Infection in the Russian Federation in 2012, http://www.hivrussia.ru/files/sprav_ 31032012.doc.

[6] Ukrainian AIDS Center, Operational Information on Officially Registered HIV-infected Citizens of Ukraine for
December 2011, http://ukraids.gov.ua/attachments/article/ 266/\%D0\%93\%D1\%80\%D1\%83\%D0\%B4\%D0\%B5\%D0\% BD\%D1\%8C\%202011.pdf.

[7] B. M. Mathers, L. Degenhardt, B. Phillips et al., "Global epidemiology of injecting drug use and HIV among people who inject drugs: a systematic review," The Lancet, vol. 372, no. 9651, pp. 1733-1745, 2008.

[8] P. Kyrychenko and V. Polonets, "High HIV risk profile among female commercial sex workers in Vinnitsa, Ukraine," Sexually Transmitted Infections, vol. 81, no. 2, pp. 187-188, 2005.

[9] W. M. Wechsberg, E. Krupitsky, T. Romanova et al., "Double jeopardy-drug and sex risks among Russian women who inject drugs: initial feasibility and efficacy results of a small randomized controlled trial," Subst Abuse Treat Prev Policy, vol. 7, article 1, 2012.

[10] L. Platt, T. Rhodes, C. M. Lowndes et al., "Impact of gender and sex work on sexual and injecting risk behaviors and their association with HIV positivity among injecting drug users in an HIV epidemic in togliatti city, Russian Federation," Sexually Transmitted Diseases, vol. 32, no. 10, pp. 605-612, 2005.

[11] E. G. Benotsch, A. M. Somlai, S. D. Pinkerton et al., "Drug use and sexual risk behaviours among female Russian IDUs who exchange sex for money or drugs," International Journal of STD and AIDS, vol. 15, no. 5, pp. 343-347, 2004.

[12] D. M. Kissin, L. Zapata, R. Yorick et al., "HIV seroprevalence in street youth, St Petersburg, Russia," AIDS, vol. 21, no. 17, pp. 2333-2340, 2007.

[13] C. L. Robbins, L. Zapata, D. M. Kissin et al., "Multicity HIV seroprevalence in street youth, Ukraine," International Journal of STD and AIDS, vol. 21, no. 7, pp. 489-496, 2010.

[14] J. R. Busza, O. M. Balakireva, A. Teltschik et al., "Streetbased adolescents at high risk of HIV in Ukraine," Journal of Epidemiology and Community Health, vol. 65, no. 12, pp. 1166-1170, 2011.

[15] International Center for Prison Studies, http://www.prisonstudies.org/.

[16] K. Dolan, B. Kite, E. Black, C. Aceijas, and G. V. Stimson, "HIV in prison in low-income and middle-income countries," The Lancet Infectious Diseases, vol. 7, no. 1, pp. 32-41, 2007.

[17] UNODC, "Handbook for Prison Managers and Policymakers on Women and Imprisonment," United Nations Publication, Sales No. E.08.IV.4, 2008, http://www.unodc.org/documents/ justice-and-prison-reform/women-and-imprisonment.pdf.

[18] R. Taylor, Women in Prison and Children of Imprisoned Mothers, Quaker United Nations Office, Geneva, Switzerland, 2004.

[19] M. Bastick and L. Townhead, Women in Prison: A Commentary on the UN Standard Minimum Rules for the Treatment of Prisoners, Quaker United Nations Office, Geneva, Switzerland, 2008.

[20] B. Bergh, A. Gatherer, A. Fraser et al., "Imprisonment and women's health: concerns about gender sensitivity, human rights and public health," Bulletin of the World Health Organization, vol. 89, no. 9, pp. 689-694, 2011.

[21] S. F. Greenfield, A. J. Brooks, S. M. Gordon et al., "Substance abuse treatment entry, retention, and outcome in women: a review of the literature," Drug and Alcohol Dependence, vol. 86, no. 1, pp. 1-21, 2007.

[22] S. Wasilow-Mueller and C. K. Erickson, "Drug abuse and dependency: understanding gender differences in etiology and management," Journal of the American Pharmaceutical Association, vol. 41, no. 1, pp. 78-90, 2001.

[23] Center for Substance Abuse Treatment, "Substance abuse treatment: addressing the specific needs of women," Tech. Rep. 
(SMA) 09-4426, Substance Abuse and Mental Health Services Administration (US), 2009.

[24] K. T. Brady and C. L. Randall, "Gender differences in substance use disorders," Psychiatric Clinics of North America, vol. 22, no. 2, pp. 241-252, 1999.

[25] O. S. Ashley, M. E. Marsden, and T. M. Brady, "Effectiveness of substance abuse treatment programming for women: a review," American Journal of Drug and Alcohol Abuse, vol. 29, no. 1, pp. 19-53, 2003.

[26] List of narcotics, psychoactive substances and their precursors subject to control in the Russian Federation, Approved by the decision of the Government of the Russian Federation, 1998, http://fskn.gov.ru/pages/main/info/official_information/7947/ index.shtml.

[27] E. Krupitsky, E. Zvartau, E. Blokhina et al., "Randomized trial of long-acting sustained-release naltrexone implant vs oral naltrexone or placebo for preventing relapse to opioid dependence," Archives of General Psychiatry, vol. 69, no. 9, pp. 973-981, 2012.

[28] E. Krupitsky, E. V. Nunes, W. Ling, A. Illeperuma, D. R. Gastfriend, and B. L. Silverman, "Injectable extended-release naltrexone for opioid dependence: a double-blind, placebocontrolled, multicentre randomised trial," The Lancet, vol. 377, no. 9776, pp. 1506-1513, 2011.

[29] E. Krupitsky, E. Zvartau, and G. Woody, "Use of naltrexone to treat opioid addiction in a country in which methadone and buprenorphine are not available," Current Psychiatry Reports, vol. 12, no. 5, pp. 448-453, 2010.

[30] E. M. Krupitsky, E. E. Zvartau, D. V. Masalov et al., "Naltrexone with or without fluoxetine for preventing relapse to heroin addiction in St. Petersburg, Russia," Journal of Substance Abuse Treatment, vol. 31, no. 4, pp. 319-328, 2006.

[31] E. M. Krupitsky, E. E. Zvartau, D. V. Masalov et al., "Naltrexone for heroin dependence treatment in St. Petersburg, Russia," Journal of Substance Abuse Treatment, vol. 26, no. 4, pp. 285-294, 2004.

[32] E. Holt, "Russian injected drug use soars in face of political inertia," The Lancet, vol. 376, no. 9734, pp. 13-14, 2010.

[33] Authors' communication with the St. Petersburg City Narcological Hospital.

[34] S. Dvoriak, "Overview of opioid substitution treatment in Ukraine," in National Conference on Harm Reduction, Kyiv, Ukraine, February 2006.

[35] Order of the Ministry of Ukraine, "On approving the order of administering the substitution supportive treatment for patients with opioid dependency," 2012, http://www.moz.gov .ua/ua/portal/dn_20120327_200.html.

[36] D. M. Kissin, M. G. Mandel, N. Akatova et al., "Five year trends in epidemiology and prevention of mother-to-child HIV transmission, S. Petersburg, Russia: results from perinatal HIV surveillance," BMC Infectious Diseases, vol. 11, article 292, 2011.

[37] Guidebook on Retaining Family Support for HIV-affected Children, St. Petersburg, Doctors to Children, 2008, http://doctors2children.ru/files/dtc_family__support__for_hiv-affected__children_.pdf.

[38] Manual on Multidisciplinary Case Management, "The Project "Prevention of Abandonment of Children Born to HIVpositive Mothers (MAMA+)",' Doctors of the World-USA, Kyiv, Ukraine, 2007.

[39] R. Yorick, S. Suvorova, O. Sukovatova et al., "Replication of the MAMA+ model to prevent child abandonment by HIVpositive women in Yekaterinburg, Russia," in Proceedings of the 19th International AIDS Conference, Washington, DC, USA, July 2012.

[40] D. Wolfe, M. P. Carrieri, and D. Shepard, "Treatment and care for injecting drug users with HIV infection: a review of barriers and ways forward," The Lancet, vol. 376, no. 9738, pp. 355-366, 2010.

[41] Golichenko, "Russia: district court upholds legal ban on opioid substitution treatment," HIV/AIDS Policy \& Law Review, vol. 15 , no. 3 , pp. $57-58,2011$.

[42] A. Shapoval, "Socioeconomic profile of HIV+ mothers including those who abandon their infants in Ukraine," in Proceedings of the 17th International AIDS Conference, Mexico City, Mexico, August 2008.

[43] H. Bailey, I. Semenenko, T. Pilipenko, R. Malyuta, and C. Thorne, "Factors associated with abandonment of infants born to HIV-positive women: results from a Ukrainian birth cohort," AIDS Care, vol. 22, no. 12, pp. 1439-1448, 2010.

[44] E. Finnerty, H. Skipalska, O. Libanov et al., "MAMA+ for injecting drug users: a pilot programme in Ukraine," in Proceedings of the 20th International Harm Reduction Conference (IHRC '09), Bangkok, Thailand, 2009.

[45] J. Beard, G. Biemba, M. Brooks et al., "Children of female sex workers and drug users: a review of vulnerability, resilience and family-centred models of care," Journal of the International AIDS Society, vol. 13, supplement 2, p. S6, 2010.

[46] "MAMA+ for Drug Using Pregnant Women and New Mothers Project in Ukraine," HealthRight International, 2010, http:// www.healthright.org.ua/en/leafletmama.

[47] Women and HIV in prison settings, UNODC, 2008, http://www.unodc.org/documents/hiv-aids/Women\%20and $\% 20$ HIV\%20in\%20prison\%20settings.pdf.

[48] Comprehensive Support to Women Released from Penitentiary Institutions. St. Petersburg, Doctors to Children, 2011, http://doctors2children.ru/publications/methodological\%20 materials/.

[49] J. Baillargeon, T. P. Giordano, J. D. Rich et al., "Accessing antiretroviral therapy following release from prison," Journal of the American Medical Association, vol. 301, no. 8, pp. 848857, 2009.

[50] J. G. Baillargeon, T. P. Giordano, A. J. Harzke, G. Baillargeon, J. D. Rich, and D. P. Paar, "Enrollment in outpatient care among newly released prison inmates with HIV infection," Public Health Reports, vol. 125, supplement 1, pp. 64-71, 2010.

[51] R. Yorick, K. Zakharov, A. Shaboltas et al., "HIV prevention and access to care for HIV-positive street youth in St. Petersburg, Russia," in Proceedings of the 17th International AIDS Conference, Mexico City, Mexico, August 2008.

[52] R. Yorick, J. Batluk, A. Shaboltas et al., "HIV prevention for street youth in St. Petersburg, Russia," in Proceedings of the 18th International AIDS Conference, Vienna, Austria, July 2010.

[53] "STEPS Prevention Training Program for Adolescents," Trainer's Guide. St. Petersburg, Doctors to Children, 2009, http://doctors2children.ru/files/DTC_STEPS_Trainer\%E2\%80 \%99s_\%20Guide\%20.pdf.

[54] "STEPS Educational Training for Adolescents," Kalita, Kyiv, Ukraine, 2010, http://www.healthright.org.ua/sites/ default/files/ourbook3.pdf.

[55] Guidebook on Integrated Assistance to Street Youth. St. Petersburg, Doctors to Children, 2009, http://doctors2children.ru/files/dtc_guidebook__assistance_to__street_youth_.pdf.

[56] Guidebook on HIV prevention and Assistance to HIVpositive Street Children and Youth. St. Petersburg, Doctors 
to Children, 2009, http://doctors2children.ru/publications/ methodological\%20materials/.

[57] Comprehensive Care and Assistance to Homeless and Neglected Children: Methodological Recommendations, Kalita, Kyiv, Ukraine, 2010.

[58] "Guidebook on Multidisciplinary Case Management in Working with Homeless Minors," HealthRight International, Kyiv, Ukraine, 2010, http://www.healthright.org.ua/sites/default/ files/ourbook2.pdf.

[59] H. Skipalska, N. Grytsaienko, R. Yorick et al., "Targeted, gender-sensitive support for street girls: linking the most vulnerable to care," in Proceedings of the 19th International AIDS Conference, Washington, DC, USA, July 2012. 


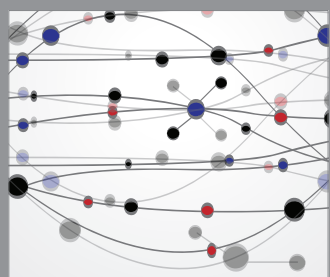

The Scientific World Journal
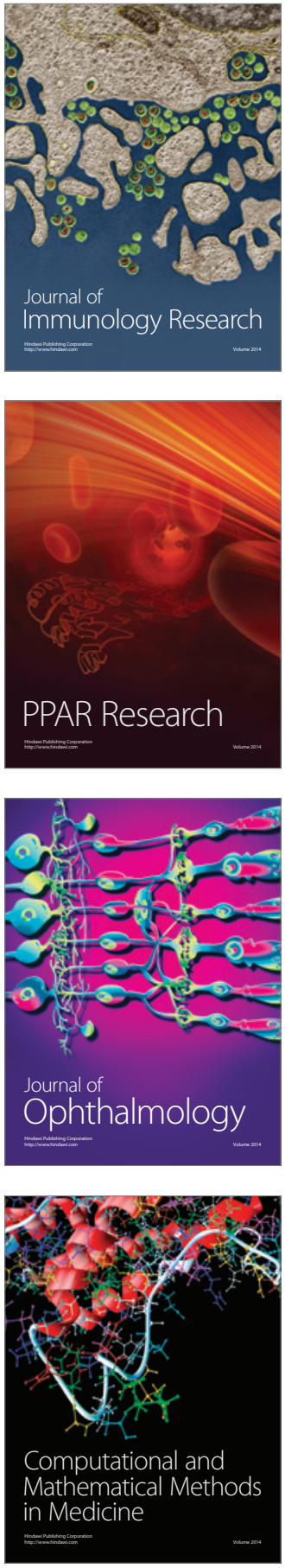

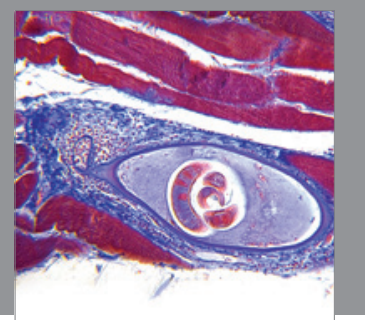

Gastroenterology

Research and Practice
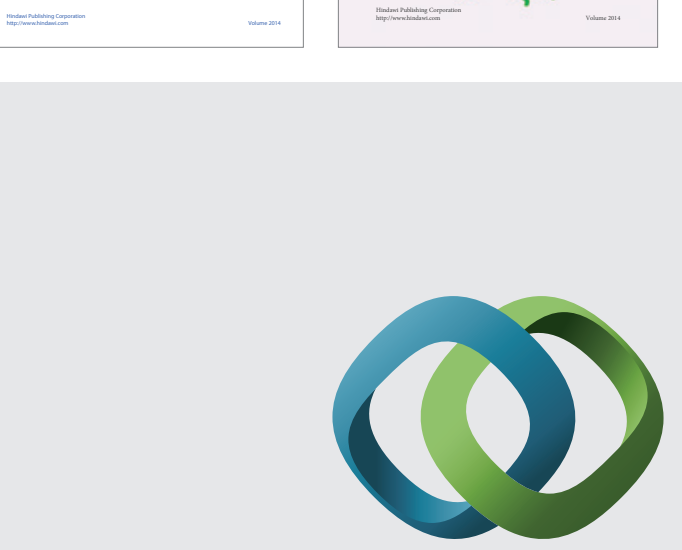

\section{Hindawi}

Submit your manuscripts at

http://www.hindawi.com
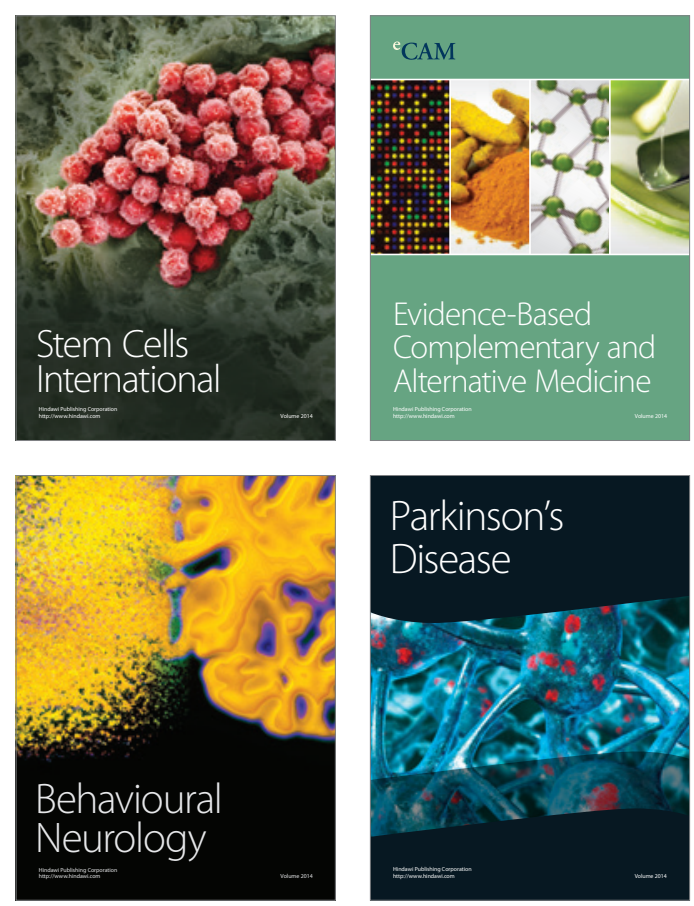

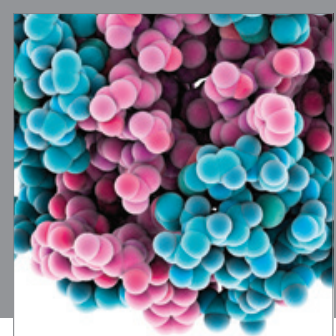

Journal of
Diabetes Research

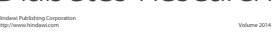

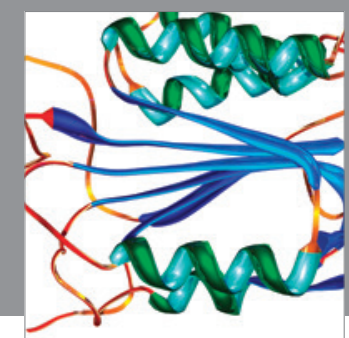

Disease Markers
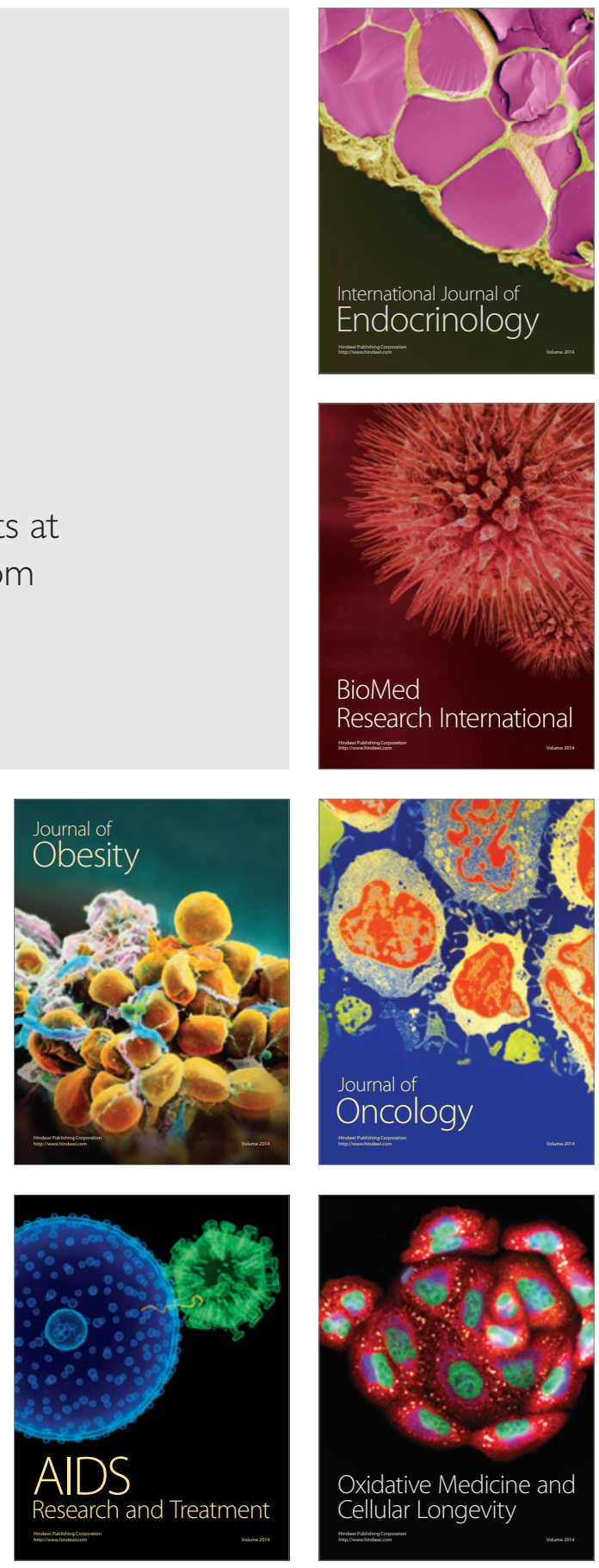